УДК 616.132.2-008.6-06:616.151.5]-07-08-039.35.

\title{
Ефективність реалізації мультимодальної безопіоїдної стратегії анестезіологічного супроводу в ранньому післяопераційному періоді хворих, прооперованих із приводу колоректального раку
}

\author{
О.О. Тенкач, А.В. Русин, Е.С. Палагонич, М.М. Кляп
}

ДВНЗ «Ужгородський національний університет», медичний факультет, кафедра онкологї; КНП «Закарпатський протипухлинний центр», Ужгород

\section{Реферат}

Вступ. Реалізація сучасних програм периопераційної та післяопераційної підтримки пацієнтів, прооперованих 3 приводу патологій раку ободової та прямої кишки, з метою забезпечення їх пришвидшеного одужування після проведення відповідних хірургічних втручань (Enhanced Recovery after Surgery - ERAS), передбачає можливості практичної імплементації протоколів анестезіологічного супроводу з мінімальним застосуванням опіоїдів або ж реалізації повністю безопіоїдних стратегій у ранньому післяопераційному періоді.

Мета дослідження: оцінити ефективність реалізації мультимодальної безопіоїдної стратегії анестезіологічного супроводу у ранньому післяопераційному періоді хворих, прооперованих з приводу колоректального раку.

Матеріали та методи. Дослідження було проведено на базі КНП «Закарпатський обласний клінічний онкологічний диспансер» у відділенні хірургії пухлин протягом 2019-2020рр. Формування досліджуваної вибірки проводилося серед пацієнтів 3 діагностично підтвердженою патологією колоректального раку та потребою в проведенні хірургічного втручання резективного характеру. Протокол загального знечулення у групі дослідження та групі порівняння був ідентичним, відмінність анестезіологічної підтримки у групі дослідження полягала у реалізації власне додаткових компонентів преемптивної та превентивної аналгезії, в той час як у групі порівняння в післяопераційному періоді купірування больового симптому забезпечувалося за рахунок застосування опіоїдів.

Інтенсивність больових відчуттів при рухах у післяопераційний період визначали за шкалою NRS. Додатково також реєстрували факт відновлення перистальтичних рухів кишківника та період розвитку таких у певний день після проведеного оперативного втручання, а також рівні систолічного артеріального тиску (САТ), діастолічного артеріального тиску (ДАТ) та частоту серцевих скорочень (ЧСС) у ранній післяопераційний період.

Результати досліджень та їх обговорення. Моніторинг показників оцінки інтенсивності больових відчуттів за шкалою NRS дозволив встановити виражену поширеність постопераційного болю середнього та високого рівнів інтенсивності у групі порівняння через 2 (серед 68\% пацієнтів) та 8 годин (серед $80 \%$ пацієнтів) після операції, в той час як поширеність болю аналогічної інтенсивності у групі реалізації безопіоїдної стратегії анестезіологічного супроводу через 2 години була у $28 \%$ пацієнтів, а через 8 годин - у 20\% пацієнтів. На 1-ий та 2-ий день після операції показники інтенсивності болю, зареєстровані у групі дослідження та групі порівняння, характеризувалися статисти-

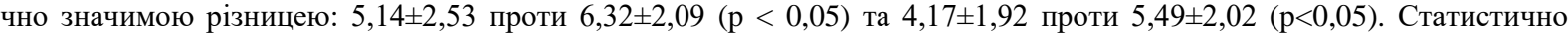
нижчі показники систолічного та діастолічного тиску, а також частоти серцевих скорочень були виявлені у групі дослідження через 2 (p<0,05) та 8 годин $(\mathrm{p}<0,05)$ після операції, а також у 2-ий $(\mathrm{p}<0,05)$ та 3 -ій дні $(\mathrm{p}<0,05)$ після хірургічного втручання, у порівнянні з групою порівняння. Відновлення перистальтики у групі дослідження було зареєстровано через $1,7 \pm 1,1$ дня після оперативного втручання, тоді як у групі контрою - через $3,5 \pm 1,2$ дня.

Висновки. Використання підходу безопіоїдного мультимодального анестезіологічного супроводу із реалізацією принципів преемптивної та превентивної аналгезії сприяє зниженню поширеності больових відчуттів середнього та сильного рівнів інтенсивності у ранній післяопераційний період, утриманню оптимальних рівнів САТ, ДАТ та ЧСС, а також пришвидшенню відновлення перистальтичних рухів кишківника у порівнянні із результатами застосування класичних протоколів загального знечулення в процесі хірургічного лікування пацієнтів із колоректальним раком та їх післяопераційної підтримки.

Ключові слова: колоректальний рак, безопіоїдна аналгезія, постопераційний супровід, біль

The effectiveness of multimodal non-opioid strategy of anaesthetic support in the early postoperative period of patients operated due to the colorectal cancer pathology

O.O. Tenkach, A.V. Rusyn, E.S Palahonych, M.M. Klyap

Department of Oncology, Faculty of Medicine, Uzhhorod National University, Uzhhorod

Transcarpathian Regional Clinical Oncology Dispensary, Uzhhorod

Abstract

Introduction. Implementation of modern programs of perioperative and postoperative support for patients with colon and rectal cancer in order to ensure their accelerated recovery after appropriate surgery (Enhanced Recovery after Surgery ERAS) provides opportunities for practical implementation of anaesthetic support protocols with full or minimal opioid use strategies in the early postoperative period.

Objective of the study. To evaluate the effectiveness of multimodal non-opioid strategy of anaesthetic support in the early postoperative period of patients operated due to the colorectal cancer pathology. 
Materials and Methods. The study was conducted on the basis of Transcarpathian Regional Clinical Oncology Dispensary at the Department of Tumor Surgery during 2019-2020. The formation of the study sample was provided among patients with diagnostically confirmed pathology of colorectal cancer and the need for resective surgery. The protocol of general anesthesia in the study group and the comparison group was identical, the difference of anaesthetic support within the study group was based on the the implementation of additional components of preemptive and preventive analgesia, while in the comparison group pain relief effect in the postoperative period was provided by the use of opioids.

The intensity of pain during movements in the postoperative period was evaluated by the NRS scale. Additionally, the recovery of peristaltic bowel movements and the period of their development on a certain day after surgery, as well as the levels of systolic blood pressure (SBP), diastolic blood pressure (DBP) and heart rate (HR) in the early postoperative period were also recorded.

Results of the study and their discussion. Monitoring of pain intensity indicators according to the NRS scale revealed a pronounced prevalence of postoperative pain of medium and high intensity levels in the comparison group at 2 (among $68 \%$ of patients) and 8 hours (among $80 \%$ of patients) after surgery, while the prevalence of pain with similar intensity in the group of non-opioid anaesthetic support strategy 2 hours after surgery was observed in $28 \%$ of patients, and 8 hours after surgery - in $20 \%$ of patients. On the 1st and 2nd day after surgery, the pain intensity values recorded in the study group and the comparison group were characterized by a statistically significant difference: $5,14 \pm 2,53$ vs. $6,32 \pm 2,09(\mathrm{p}<0,05)$ and $4,17 \pm 1,92$ vs. $5,49 \pm 2,02(\mathrm{p}<0,05)$ respectively. Statistically lower systolic and diastolic blood pressure values, as well as heart rate levels were observed in the study group $2(\mathrm{p}<0,05)$ and 8 hours $(\mathrm{p}<0,05)$ after surgery, as well as at the 2 nd $(\mathrm{p}<0,05)$ and the 3rd day $(\mathrm{p}<0,05)$ after surgery compare with the control group. Restoration of peristalsis in the study group was registered at $1,7 \pm 1,1$ days after surgery, while in the control group at $3,5 \pm 1,2$ days after surgery.

Conclusions. The use of non-opioid multimodal anesthesia with the implementation of preemptive and preventive analgesia principles helps to reduce the prevalence of medium and severe intensity pain in early postoperative period, to maintain optimal levels of SBP, DBP and heart rate, and to accelerate the recovery of peristaltic bowel movements compared to the results obtained with the use of classical protocols of general anesthesia during the surgical treatment of patients with colorectal cancer and their postoperative support.

Key words: colorectal cancer, non-opioid analgesia, postoperative support, pain

Вступ. Проблема ефективного медикаментозного купірування больових відчуттів у післяопераційний період залишається актуальною у сучасній анестезіологічній та хірургічній практиці, зважаючи на те, що в результаті вираженого больового симптому після проведення хірургічних втручань відстрочується період мобілізації пацієнта, спостерігаються негативні клінічно-значимі зміни у низці органів та систем, а також знижується прогноз подальшої ефективної реабілітації з огляду на ризик розвитку потенційних ускладнень [1, $2,3,4,5]$. Крім того, вираженість больових відчуттів безпосередньо пов'язана і 3 вартісною складовою лікування, враховуючи потребу забезпечення пацієнта додатковими фармакологічними середниками та вимушене пролонговане його перебування в умовах стаціонару $[6,7,8]$.

3 урахуванням факту проведення близько 300 мільйонів різних хірургічних втручань щороку [9], та частоту реєстрації випадків патології колоректального раку як третього найбільш поширеного виду неоплазії (близько 1,2 мільйона випадків щороку) [10], доцільність подальшого дослідження ефективності реалізації різних алгоритмів аналгезії в постопераційний період серед хворих, прооперованих $з$ приводу раку ободового та/або прямого кишківника, можна вважати достатньо аргументованою та релевантною.

Дані Бюлетеню національного канцер-реєстру України №21 «Рак в Україні 2018-2019» свідчать про загальну кількість 9195 випадків раку ободової кишки та 7480 випадків раку прямої кишки за проаналізований період. Показник захворюваності для вищезгаданих патологій сягав 25,6 та 20,9 відповідно, і при цьому 68\% первинних хворих із раком ободової кишки та $74 \%$ із раком прямої кишки отримали відповідне спеціальне лікування, $38,2 \%$ і 21,2\%, відповідно, - лише хірургічне, а $23,5 \%$ і 33,2\%, відповідно, - комбіноване та комплексне. В умовах когортного дослідження було відзначено, що більшість пацієнтів (до 50-64\%), зокрема і пацієнтів молодого віку, після виконання оперативних втручань 3 приводу раку ободової кишки, характеризуються розвитком больових відчуттів середнього і важкого рівнів інтенсивності [10]. Аналіз траєкторій змін показників інтенсивності постопераційного болю серед пацієнтів, прооперованих із приводу колоректального раку, також виявив, що близько у 9,7\% пацієнтів інтенсивність больових відчуттів зростає 3 середнього рівня вираженості до важкого [11].

Реалізація сучасних програм периопераційної та післяопераційної підтримки пацієнтів, прооперованих із приводу патологій раку ободової та прямої кишки, з метою забезпечення їх пришвидшеного одужування після проведення відповідних хірургічних втручань (Enhanced Recovery after Surgery - ERAS) передбачає можливості практичної імплементації протоколів анестезіологічного супроводу 3 мінімальним застосуванням опіоїдів або ж реалізації повністю безопіоїдних стратегій у ранньому післяопераційному періоді [12, 13, 14]. Адаптовані доказово-доведені клінічні настанови щодо діагностики та лікування колоректального раку, опубліковані Державним експертним центром МО3 України (2016), також містять інформацію про необхідність впровадження комплексного мультидисциплінарного підходу 3 метою купірування больових відчуттів не тільки за допомогою опіоїдів, а й інших препаратів, зокрема амітриптиліну, кетаміну та габапентину. Крім того реалізація мультимодальних підходів аналгезії 3 
мінімізацією обсягу використовуваних опіоїдів включено до сукупності доказово-аргументованих рекомендацій міжнародної робочої групи PROSPECT, цільовим завданням якої є формулювання консенсусних рішень щодо процедурноспецифічного постопераційного купірування болю [15].

Мета дослідження: оцінити ефективність реалізації мультимодальної безопіоїдної стратегії анестезіологічного супроводу у ранньому післяопераційному періоді хворих, прооперованих 3 приводу колоректального раку.

Матеріали та методи. Дослідження було проведено на базі КНП «Закарпатський обласний клінічний онкологічний диспансер» у відділенні хірургії пухлин протягом 2019-2020 рр. Формування досліджуваної вибірки пацієнтів 3 діагностично підтвердженою патологією колоректального раку та потребою в проведенні хірургічного втручання резективного характеру проводилося з урахуванням наступних критеріїв включення: 1) відсутність ознак метастазування та ураження лімфатичних вузлів (відповідність стадіям $\mathrm{T}_{2-3} \mathrm{~N}_{0} \mathrm{M}_{0}$ ); 2) приналежність пацієнтів до 2 або 3 стадій за ASA; 3) отримання інформованої добровільної згоди пацієнта щодо участі у дослідженні. Виражена серцева недостатність (фракція викиду $<30 \%)$, факт інфаркту в анамнезі у період менше одного місяця, порушення ритму або ж провідності були використані як критерії виключення. Рандомізовано пацієнтів було розподілено на групу дослідження (25 осіб), в якій анестезіологічний супровід здійснювали згідно 3 мультимодальною безопіоїдною стратегією, та групу порівняння (25 осіб), в якій забезпечували реалізацію класичного опіоїдного супроводу у післяопераційний період.

У групі дослідження забезпечували таку схему анестезіологічного супроводу:

- до початку оперативного втручання: прегабалін - 150 мг per os за 12 год до операції, ацетамінофен - 1000 мг в/в до розрізу шкіри, MgSO4 25\% - 2500 мг в/в до розрізу шкіри, дексаметазон 8 мг в/в до розрізу шкіри, декскетопрофен 50 мг в/в до розрізу шкіри (преемптивна аналгезія);

- епідуральна анестезія на рівні Th XI-XII за стандартною методикою 3 уведенням розчину лонгокаїну $0,25 \%$ - 4,0 мл як контрольну тестдозу, та $0,125 \%$ розчин лонгокаїну з комбінацією фентанілу 2 мкг/мл на інфузоматі 3 розрахунку 5,5-9,5 мл/год;

- індукційний компонент: розчин діпрофолу $1 \%$ $2,0-2,5$ мг/кг маси тіла в/в, атракуріум 0,5-0,6 мг/кг, через 90 сек проводилася інтубація трахеї;

- підтримка анестезії: розчин діпрофолу $1 \%$ на інфузоматі 4-10 мкг/кг/год;

- міорелаксація: розчин атракуріуму у дозі $0,1-$ 0,2 мг/кг;

- після закінчення оперативного втручання: нефопам 20 мг/мл - 2,0 мл в/м кожні 8 год (1 доба); ацетамінофен - 1000 мг в/в кожні 8 год (3 доби); декскетопрофен - 50 мг в/в кожні 8 год (3 доби).

Анестезіологічне забезпечення у групі порівняння було реалізовано таким чином:

- індукційний компонент: розчин діпрофолу $1 \%-2,0-2,5$ мг/кг маси тіла в/в, атракуріум 0,5 0,6 мг/кг, через 90 сек проводилася інтубація траxeї;

- підтримка анестезії: розчин діпрофолу $1 \%$ на інфузоматі 4-10 мкг/кг/год;

- міорелаксація: розчин атракуріуму в дозі 0,1 $0,2 \mathrm{мг} / \mathrm{кг}$

По суті протокол загального знечулення у групі дослідження та групі порівняння був ідентичним, відмінність анестезіологічної підтримки у групі дослідження полягала у реалізації власне додаткових компонентів преемптивної та превентивної аналгезії, в той час як у групі порівняння в післяопераційному періоду купірування больового симптому забезпечувалося за рахунок застосування опіоїдів.

Інтенсивність больових відчуттів при рухах у післяопераційний період визначали за шкалою NRS 3 такою інтерпретацією показників серед кожного пацієнта: 0 - відсутність болю, 1-3 - помірний біль, 4-6 - біль середнього рівня інтенсивності, 7-10 біль сильного рівня інтенсивності [16].

Оцінку фактів нудоти та блювання у післяопераційний період проводили у відповідності до категоризації Barclay та колег: 1) ранній тип, мінімальна кількість; 2) ранній тип, виражена кількість без ознак дисфункції шлунка; 3) пізній тип, мінімальна кількість; 4) пізній тип, виражена кількість [17]. Додатково також реєстрували факт відновлення перистальтичних рухів кишківника та період розвитку таких у певний день після проведеного оперативного втручання, а також рівні систолічного артеріального тиску (САТ), діастолічного артеріального тиску (ДАТ) та частоту серцевих скорочень (ЧСС) у ранній післяопераційний період.

Нормальний характер розподілу даних підтверджували із застосування критерію узгодженості Колмогорова-Смирнова. Для порівняння показників аналогічних параметрів між двома групами та встановлення рівня їх відмінностей використовували параметричний критерій Стьюдента 3 урахуванням досягнутої значущості при $p<0,05$. Систематизацію та групування даних проводили у табличному редакторів Microsoft Excel 2019 (Microsoft Office, 2019), a їх аналітичне статистичне опрацювання за допомогою пакету програмного забезпечення «STATISTICA 10.0» (Statsoft).

Результати досліджень та їх обговорення. Дескриптивні характеристики групи дослідження та групи порівняння представлені у таблиці 1 . Статистично значущих відмінностей між групами щодо параметрів розподілу за статтю ( $>0,05)$, середніх показників віку $(\mathrm{p}>0,05)$, ваги $(\mathrm{p}>0,05)$, зросту $(\mathrm{p}>0,05)$ та часу проведення операції $(\mathrm{p}>0,05)$ зареєстровано не було. 
Дескриптивні характеристики груп дослідження та порівняння

\begin{tabular}{|l|l|l|}
\hline & \multicolumn{1}{|c|}{ Група порівняння $(\mathrm{n}=25)$} & \multicolumn{1}{c|}{ Група дослідження $(\mathrm{n}=25)$} \\
\hline Чоловіки/жінки & $16 / 9$ & $14 / 11$ \\
\hline Вік & $62,3 \pm 10,1$ & $60,7 \pm 8,7$ \\
\hline Вага, кг & $78 \pm 18,1$ & $76 \pm 17,4$ \\
\hline Зріст, см & $167 \pm 7,7$ & $170 \pm 9,2$ \\
\hline Час операції, хв & $155 \pm 39$ & $161 \pm 37$ \\
\hline Інтраопераційна анестезія & Загальна анестезія & Загальна анестезія \\
\hline Післяопераційна аналгезія & Опіоїди & Безопіоїдна стратегія \\
\hline
\end{tabular}

Моніторинг показників оцінки інтенсивності больових відчуттів за шкалою NRS дозволив встановити виражену поширеність постопераційного болю середнього та високого рівнів інтенсивності у групі порівняння через 2 (серед 68\% пацієнтів) та 8 годин (серед 80\% пацієнтів) після операції, в той час як поширеність болю аналогічної інтенсивності у групі реалізації безопіоїдної стратегії анестезіологічного супроводу через 2 години була відзначена у $28 \%$ пацієнтів, а через 8 годин - у
20\% пацієнтів. На 1-ий та 2-ий день після операції показники інтенсивності болю, зареєстровані у групі дослідження та групі порівняння, характеризувалися статистично значимою різницею: $5,14 \pm 2,53$ проти $6,32 \pm 2,09(\mathrm{p}<0,05)$ та $4,17 \pm 1,92$ проти 5,49 $\pm 2,02$ (р<0,05); статистична значущість зареєстрованих відмінностей показників інтенсивності болю на 3-5 день після операції не була підтвердженою в ході проведення аналітичного опрацювання даних двох груп (рис. 1).

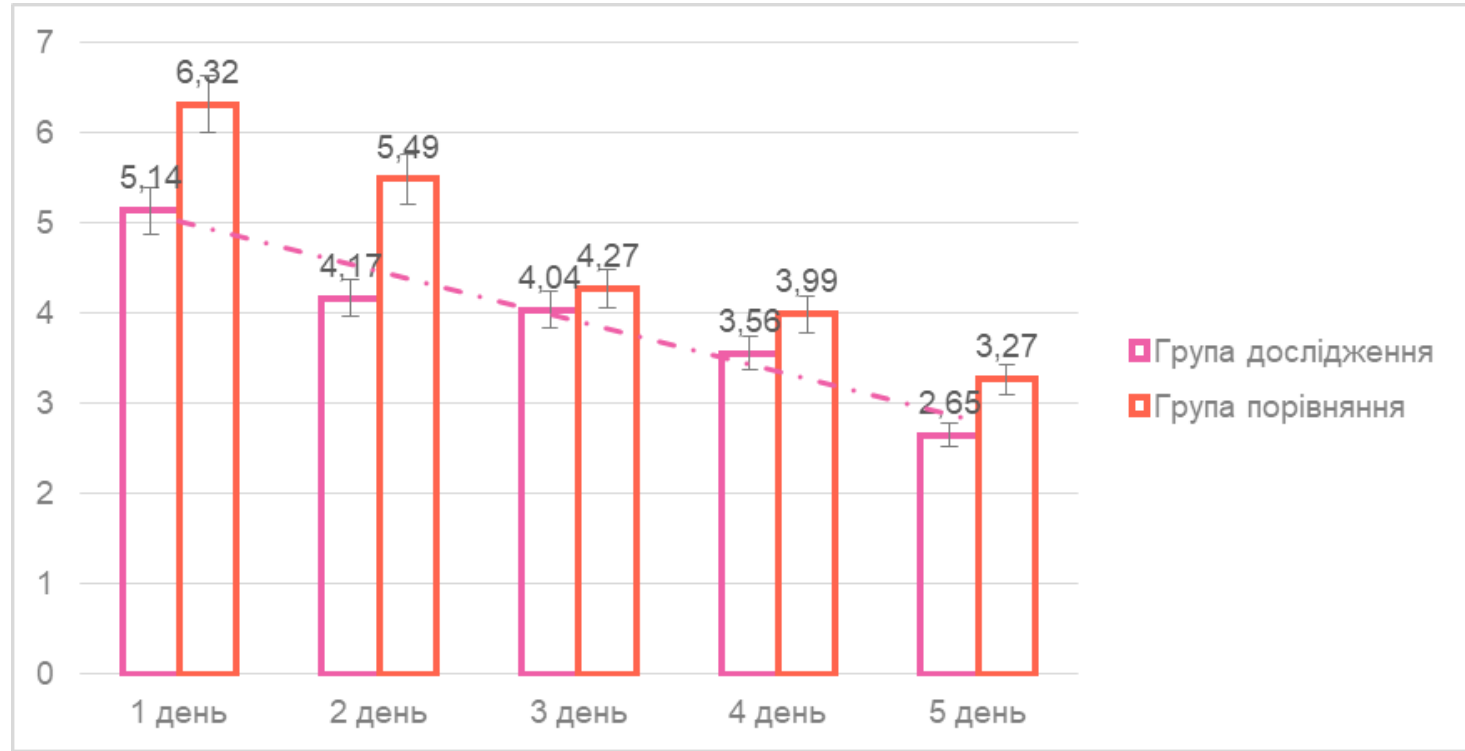

Рис. 1. Порівняння показників інтенсивності болю за шкалою NRS.

Поширеність нудоти та блювоти у ранньому післяопераційному періоді серед пацієнтів групи дослідження складала $68 \%$, а серед пацієнтів групи порівняння $76 \%$, різниця між котрими не була статистично підтвердженою ( $>0,05)$. При стратифікації усіх патернів постопераційної нудоти та блювання згідно Barclay та колег, поширеність лише пізнього типу з вираженою кількістю у групі порівняння була статистично вищою, ніж у групі дослідження $(\mathrm{p}<0,05)$.

Статистично нижчі показники систолічного та діастолічного тиску, а також частоти серцевих скорочень були відмічені у групі дослідження через $2(\mathrm{p}<0,05)$ та 8 годин $(\mathrm{p}<0,05)$ після операції, а також у 2-ий $(\mathrm{p}<0,05)$ та 3-ій дні $(\mathrm{p}<0,05)$ після хірургічного втручання, у порівнянні із групою контролю.

Відновлення перистальтики у групі дослідження було зареєстровано через $1,7 \pm 1,1$ дня після оперативного втручання, тоді як у групі контролю - через 3,5 1,2 дня.

Отримані результати свідчать про досягнутий позитивний ефект використання безопіоїдної стратегії мультимодального анестезіологічного супроводу, який сприяє зниженню поширеності больових відчуттів середнього та сильного рівнів інтенсивності у ранній післяопераційний період, утриманню оптимальних рівнів САТ, ДАТ та ЧСС, а також пришвидшенню відновлення перистальтичних рухів кишківника. 
Потреба ефективного купірування больових відчуттів серед хворих, прооперованих із приводу колоректального раку, була підтверджена застосуванням уніваріативних моделей регресійного аналізу, які встановили, що зростаючий характер траєкторій показників інтенсивності постопераційного болю у хворих асоційований із підвищеним ризиком потенційного рецидиву патології та скороченням загальної тривалості виживання. В свою чергу фактори, що впливали на розвиток больового симптому у період після проведення резекції ободової кишки включали вік, патологію діабету, проведення переливання крові в анамнезі, лімфосудинну інвазію пухлини, проведення хімо- та/або ж радіотерапії передопераційно [11]. Мультиваріативні моделі регресійного аналізу виявили вплив ще низки чинників, значимість ролі яких у потенційному прогнозі розвитку рецидиву чи скорочення терміну загального виживання пацієнтів, прооперованих 3 приводу колоректального раку, у порівнянні із наявністю больового симптому постопераційно була більш статистично вираженою [11]. Отримані результати свідчать про потребу подальшого вивченням сукупності взаємозв'язків між похідними параметрами оперативного втручання, особливостями розвитку колоректального раку та специфікою аналгетичного супроводу, як таких, що характеризуються відповідним впливом на прогноз постопераційного безрецидивного виживання пацієнтів пролікованих 3 приводу раку прямої та ободової кишки.

Ефективність описаної вище безопіоїдної стратегії мультимодального анестезіологічного супроводу також підтверджена доказовими рекомендаціями щодо менеджменту больових відчуттів при проведенні лапароскопічних оперативних втручань iз приводу колоректального раку у післяопераційний період, сформульованими за результатами систематичного огляду та даними робочої групи PROSPECT (процедурно-специфічного постопераційного купірування болю), які передбачають [15]:

- при високій інтенсивності болю (показники $\mathrm{VAS} \geq 50$ мм) застосування інгібіторів циклооксигенази-2 або нестероїдних протизапальних препаратів, парацетамолу та внутрішньовенної пацієнтконтрольованої опіоїдної аналгезії;

- при середній або ж низькій інтенсивності болю (VAS<50 мм) використання інгібіторів циклооксигенази-2 або нестероїдних протизапальних препаратів, парацетамолу та можливе застосування слабких опіоїдів 3 цільовою направленістю модифікації лікувальних схем до мультимодальних варіантів супроводу [15].

В умовах рандомізованого дослідження було доведено, що схему анестезіологічного супроводу на основі інфільтрації рани ропівакаїном можна розцінювати як аналогічно-ефективну альтернативу опіоїд-орієнтованим підходам до купірування постопераційного болю, зважаючи на зареєстрова- ні показники функції імунної системи, частоту рецидивів та метастазування впродовж 1-річного моніторингу за пацієнтами, прооперованих із приводу колоректального раку [18]. Аналогічні результати ефективності реалізації схем безопіоїдного супроводу в розрізі їх можливостей щодо купірування больових відчуттів із досягнення рівня терапевтичного ефекту аналогічного опіоїдам були описані і в низці попередніх досліджень [20, 21, $22,23]$. Хоча за даними систематичного огляду досі не встановлено чітких доказів того, що застосування опіоїдів у післяопераційний період із метою купірування болю, асоційовано із підвищеним ризиком рецидиву патології колоректального раку, в той час як розвиток виражених больових відчуттів як таких в більшій мірі був пов'язаний із порушеннями у функції різних систем та органів, відтак нівелювання больового симптому та зниження можливості його хронізації повинно виступати як одна 3 цільових терапевтичних прерогатив післяопераційної підтримки [24].

Консенсусним на сьогодні $є$ принцип прогнозування показників післяопераційної виживаності пацієнтів, пролікованих 3 приводу колоректального раку, з огляду на особливості взаємозв'язків похідних трьох основних параметрів: характеристики прогресування неопластичної патології, специфіки проведення хірургічного втручання та складових анестезіологічного супроводу в перита післяопераційний періоди, а також даних анамнезу (вплив індивідуально-асоційованих факторів). Відтак перспектива подальших досліджень включає вивчення впливу хірургічноасоційованих факторів (типу проведеної оперативної маніпуляції, обсягу втручання, тривалості операції) на можливість розвитку вираженого больового симптому у післяопераційний період за умов реалізації аналогічних схем анестезіологічного супроводу серед пацієнтів різного віку та iз різним анамнезом. Даний вектор досліджень сприятиме адаптації доказово-аргументованих схем превентивної та преемптивної аналгезії 3 урахуванням індивідуальних умов кожної окремої клінічної ситуації, зважаючи на варіативність больових проявів, зареєстровану у низці попередньо проведених клінічних спостережень. Крім того, реалізація досліджень проспективного дизайну дозволить визначити, наскільки реалізація більш інтенсивних або ж опіоїд-альтернативних (безопіоїдних) схем аналгезії впливатиме на зниження частоти розвитку рецидивів та зниження рівня смертності серед пацієнтів, пролікованих із приводу колоректального раку, у віддалений постоперативний період.

Висновки. 1. Використання підходу безопіоїдного мультимодального анестезіологічного супроводу із реалізацією принципів преемптивної та превентивної аналгезії сприяє зниженню поширеності больових відчуттів середнього та сильного рівнів інтенсивності у ранній післяопераційний 
період, утриманню оптимальних рівнів САТ, ДАТ та ЧСС, а також пришвидшенню відновлення перистальтичних рухів кишківника у порівнянні із результатами застосування класичних протоколів загального знечулення в процесі хірургічного лікування пацієнтів із колоректальним раком та ї післяопераційної підтримки.

2. Мінімізація потреби у застосуванні опіоїдів серед пацієнтів, прооперованих 3 приводу раку ободового та/або прямого кишківника, у післяопераційному періоді потенційно зменшує обсяг витрат, пов'язаних із лікуванням, за рахунок пришвидшеної реабілітації, скорочення необхідного терміну перебування пацієнта в умовах стаціонару та зниження ризику розвитку ускладнень, асоційованих із можливим негативним впливом опіоїдів на функціональний стан окремих систем та органів.

Інформація про конфлікт інтересів. Автори заявляють про відсутність конфлікту інтересів при виконанні наукового дослідження та підготовці даної статті.

Інформація про фінансування. Автори гарантують, що вони не отримували жодних винагород у будь-якій формі, здатних вплинути на результати роботи.

Особистий внесок кожного автора у виконання роботи:

Тенкач О.О., Русин А.В. - ідея, розпрацювання мети, контроль процесу дослідження.

Палагонич Е.С. - збір та аналіз даних, корекція помилок.

Кляп М.М. - створення діаграм, дизайну статті, оформлення за вимогами редакції.

\section{Список використаної літератури}

1. Rawal N. Current issues in postoperative pain management. European Journal of Anaesthesiology (EJA). 2016; 33(3):160-71.

2. Hong KY, Kim DK, Park HJ, Sim WS, Wi WG, Lee WY, Kim HC, Lee JY. Analgesic efficacy of preemptive transversus abdominis plane block in patients undergoing laparoscopic colorectal cancer surgery. Journal of Clinical Medicine. 2020; 9(5):1577.

3. Page GG. Surgery-induced immunosuppression and postoperative pain management. AACN Advanced Critical Care. 2005;16(3):302-9.

4. Gan TJ. Poorly controlled postoperative pain: prevalence, consequences, and prevention. Journal of pain research. 2017; 10:2287.

5. Niraj G, Rowbotham DJ. Persistent postoperative pain: where are we now?. British journal of anaesthesia. 2011; 107(1):25-9.

6. Shaffer EE, Pham A, Woldman RL, Spiegelman A, Strassels SA, Wan GJ, Zimmerman T. Estimating the effect of intravenous acetaminophen for postoperative pain management on length of stay and inpatient hospital costs. Advances in therapy. 2016; 33(12):2211-28.

7. Bardiau FM, Taviaux NF, Albert A, Boogaerts JG, Stadler M. An intervention study to enhance postoperative pain management. Anesthesia \& analgesia. 2003; 96(1):179-85.

8. Ong CK, Lirk P, Seymour RA, Jenkins BJ. The efficacy of preemptive analgesia for acute postoperative pain management: a meta-analysis. Anesthesia \& Analgesia. 2005; 100(3):757-73.

9. Steyaert A, Lavand'homme P. Prevention and treatment of chronic postsurgical pain: a narrative review. Drugs. 2018; 78(3):339-54.

10. Lindberg M, Franklin O, Svensson J, Franklin KA. Postoperative pain after colorectal surgery. International journal of colorectal disease. 2020; 35:1265-72.

11. Chang WK, Tai YH, Lin SP, Wu HL, Tsou MY, Chang KY. An investigation of the relationships between postoperative pain trajectories and outcomes after surgery for colorectal cancer. Journal of the Chinese Medical Association. 2019; 82(11):865-71.

12. Gustafsson UO, Hausel J, Thorell A, Ljungqvist O, Soop M, Nygren J. Adherence to the enhanced recovery after surgery protocol and outcomes after colorectal cancer surgery. Archives of surgery. 2011; 146(5):571-7.

13. King PM, Blazeby JM, Ewings P, Longman RJ, Kipling RM, Franks PJ, Sheffield JP, Evans LB, Soulsby M, Bulley SH, Kennedy RH. The influence of an enhanced recovery programme on clinical outcomes, costs and quality of life after surgery for colorectal cancer. Colorectal disease. 2006; 8(6):506-13.

14. Ljungqvist O, Scott M, Fearon KC. Enhanced recovery after surgery: a review. JAMA surgery. 2017; 152(3):292-8.

15. Joshi GP, Van de Velde M, Kehlet H, PROSPECT Working Group Collaborators, Pogatzki-Zahn E, Schug S, Bonnet F, Rawal N, Delbos A, Lavand'homme P, Beloeil H. Development of evidence-based recommendations for procedure-specific pain management: PROSPECT methodology. Anaesthesia. 2019; 74(10):1298-304.

16. Hawker GA, Mian S, Kendzerska T, French M. Measures of adult pain: Visual analog scale for pain (vas pain), numeric rating scale for pain (nrs pain), mcgill pain questionnaire (mpq), short-form mcgill pain questionnaire (sf-mpq), chronic pain grade scale (cpgs), short form-36 bodily pain scale (sf-36 bps), and measure of intermittent and constant osteoarthritis pain (icoap). Arthritis care \& research. 2011; 63(S11):S240-52. 
17. Barclay KL, Zhu YY, Tacey MA. Nausea, vomiting and return of bowel function after colorectal surgery. ANZ journal of surgery. 2015; 85(11):823-8.

18. Kim SY, Kim NK, Baik SH, Min BS, Hur H, Lee J, Noh HY, Lee JH, Koo BN. Effects of Postoperative Pain Management on Immune Function After Laparoscopic Resection of Colorectal Cancer: A Randomized Study. Medicine. 2016; 95(19):e3602.

19. Keller DS, Zhang J, Chand M. Opioid-free colorectal surgery: a method to improve patient \& financial outcomes in surgery. Surgical endoscopy. 2019; 33(6):1959-66.

20. Helander EM, Webb MP, Bias M, Whang EE, Kaye AD, Urman RD. A comparison of multimodal analgesic approaches in institutional enhanced recovery after surgery protocols for colorectal surgery: pharmacological agents. Journal of Laparoendoscopic \& Advanced Surgical Techniques. 2017; 27(9):903-8.

21. Aryaie AH, Lalezari S, Sergent WK, Puckett Y, Juergens C, Ratermann C, Ogg C. Decreased opioid consumption and enhance recovery with the addition of IV Acetaminophen in colorectal patients: a prospective, multi-institutional, randomized, double-blinded, placebo-controlled study (DOCIVA study). Surgical endoscopy. 2018; 32(8):3432-8.

22. Mujukian A, Truong A, Tran H, Shane R, Fleshner P, Zaghiyan K. A standardized multimodal analgesia protocol reduces perioperative opioid use in minimally invasive colorectal surgery. Journal of Gastrointestinal Surgery. 2019; 12:1-9.

23. Lohsiriwat V. Opioid-sparing effect of selective cyclooxygenase-2 inhibitors on surgical outcomes after open colorectal surgery within an enhanced recovery after surgery protocol. World journal of gastrointestinal oncology. 2016; 8(7):543.

24. Diaz-Cambronero O, Mazzinari G, Cata JP. Perioperative opioids and colorectal cancer recurrence: a systematic review of the literature. Pain management. 2018; 8(5):353-61.

\section{Стаття надійшла до редакції: 16.11.2020 р.}

